\title{
Healthcare Energy Metering Guidance
}

\section{Introduction}

This brochure is intended to help facility and energy managers plan and prioritize investments in energy metering. It offers healthcarespecific examples of metering installations, benefits, and steps that other health systems can reproduce. It reflects collaborative input from the U.S. Department of Energy (DOE) national laboratories and the health system members of the DOE Hospital Energy Alliance's Benchmarking and Measurement Project Team.

If you are just starting to explore metering improvements, you can begin by taking low-cost steps to fully leverage resources in existing buildings. Similarly, as you design new facilities, careful decisions upfront can significantly reduce metering costs later. You can follow these steps as needed with investments in data collection improvements or additional meters. With each enhancement, you should evaluate how the new metered data are being used to ensure that metering investments are leading to energy-saving actions or portfolio improvements. Figure 1 summarizes the overall iterative process of developing a metering program.

\section{Contents include:}

\section{Introduction}

Basic Stages and Steps

for Building a Metering Program

\section{Hospital Case 1}

Low-Cost/No-Cost Metering With Existing Resources

\section{Hospital Case 2}

Making Cost-Effective Decisions Early in the Hospital Design Process

\section{Hospital Case 3}

Getting the Most out of Physical Meters

\section{Considerations When Prioritizing Metering Investments}

\section{Example Template 1} Language for a Metering Data Acquisition System Request for Proposal

\section{Example Template $\mathbf{2}$} Language To Support Metering Within a Building Design Request for Proposal

\section{Additional Information}

\section{Figure 1. Basic stages and steps for building a metering program $\nabla$}

Illustration by Feitau Kung and Raymond David/NREL

\begin{tabular}{l|l} 
First Stage: \\
Low/No Cost
\end{tabular}$\quad \begin{aligned} & \text { Second Stage: } \\
& \text { Early Investments }\end{aligned} \quad \begin{aligned} & \text { Subsequent Iterations: } \\
& \text { Building Up Your Metering Capabilities }\end{aligned}$

Establish goals and scope for metering.

In new buildings, design electrical distribution and gas and water piping to accommodate near term and long term metering needs.

See page 3 for more information.

\section{In existing buildings,}

look for metering capabilities in existing equipment (e.g. automatic transfer switches, distribution panels, motor control centers, variable frequency drives) See page 2 for more information.

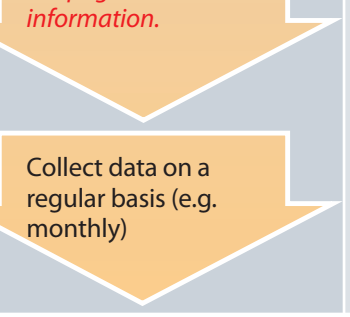

Record data in a dedicated database. Check meters periodically for accuracy and recalibrate as needed. Analyze data regularly to evaluate performance and identify opportunities for energy saving actions.

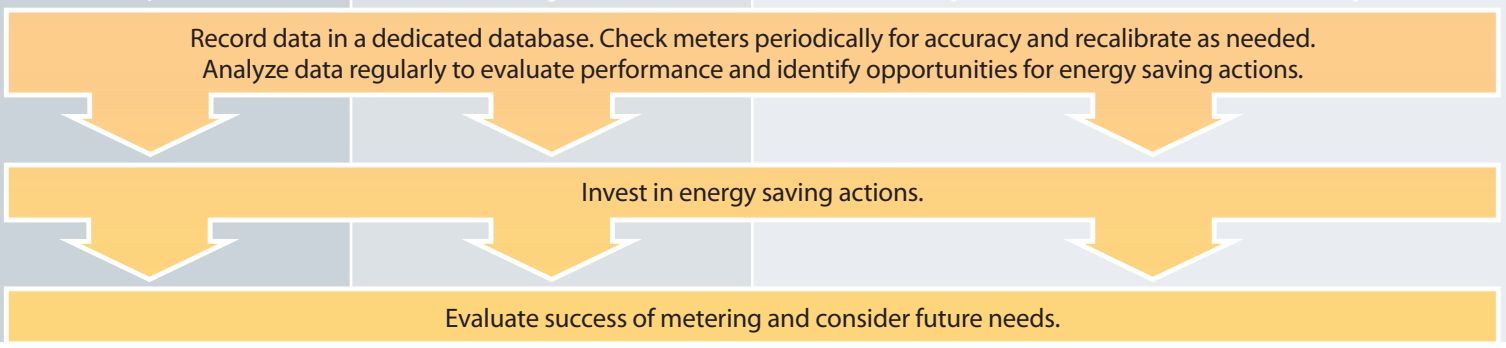

Evaluate success of metering and consider future needs.

Identify high priority targets for:

Building-level metering

- Metering of spaces (e.g. spaces with different functions, additions)

- Metering of end uses (e.g. lighting, reheat, medical equipment)

See page 6 for more information.

When evaluating options for metering system hardware, software, or services: understand the provider's cost model up front. Some cost models can make later addition of meters, or connections of additional measurement points to software, cost prohibitive.
Invest in metering systems, including physical meters and/or automation of data collection.
Determine whether desired capabilities can be achieved with virtual/indirect metering that leverages existing metering points or whether additional physical meters are needed.

If possible, invest in virtual or indirect metering that leverages existing metering points. See page 4 for more information.
If necessary, invest in additional physical meters. 


\section{PeaceHealth-St. Joseph Medical Center $\nabla$}

Location: Bellingham, Washington

Size: 253 beds; $510,000 \mathrm{ft}^{2}$

Functions: Acute care, ambulatory surgery

Photo by PeaceHealth, used by permission.

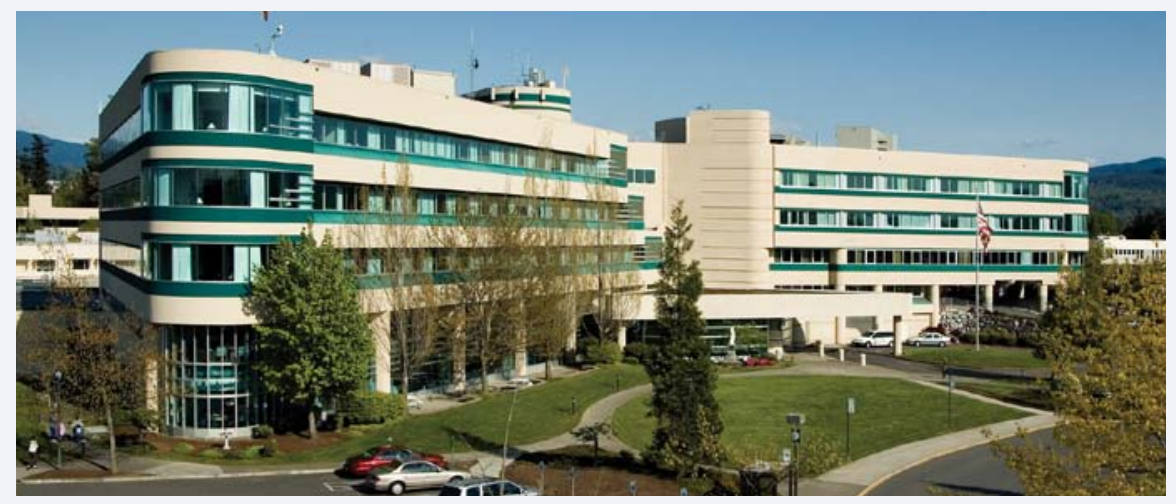

\section{Background $\nabla$}

PeaceHealth's St. Joseph Medical Center decided to pursue metering to enable the following actions:

- Confirm energy conservation project performance.

- Establish tracking of individual loads for troubleshooting and targeting energy conservation opportunities.

- Validate seasonal load performance.

- Establish a basis for raising end user awareness and possible future departmental back billing.

PeaceHealth found that searching for and fully leveraging installed metering capabilities was an important, cost-effective first step in its metering efforts.

\section{Scope of Metering $\nabla$}

Staff identified energy metering capabilities present in installed equipment. They began to meter substations, automatic transfer switches, motors equipped with variable frequency drives (VFDs), and lighting panels in 2009. The metering scope involved no material costs; the only new cost was the staff time used to read the meters. The time required to read, record, and analyze data from 70 points is approximately one staff day per month. Future automation of this function through the building automation system would substantially reduce staff time.

\section{Example Success}

These metering activities led the facility owner to justify staff time required to target money-saving actions and exercise good stewardship. The facility owner implemented a project to reduce fan horsepower in the surgery suites during unoccupied hours with the use of occupancy sensor control of variable air volume boxes. Effectiveness was substantiated by monitoring energy use at the supply and return fans' VFD kilowatt-hour counters. The measure cost about $\$ 29,000$ and saved about $\$ 21,000$ per year, paying back in less than 2 years.

Because of this success, another patient area served by a large air handler has since been targeted for a similar upcoming retrofit. Also, high-intensity discharge lighting in the parking garage will soon be converted to fluorescent lighting. Baseline performance determined through existing panel metering is being used to both establish savings potential and validate project effectiveness.

\section{Recommended Steps for Hospitals $\nabla$}

\section{The target audience for this approach includes health systems that:}

- Are just starting their metering efforts.

- Have no substantial automated data collection capabilities in place.

This approach is more likely to succeed for health systems that:

- Assign dedicated energy management personnel, even if only part time.

- Identify staff or volunteers who are energy champions. These could include personnel in executive leadership positions or a "green team" of personnel at various levels.

- Establish a strategic energy management plan. (See http:// www.betterbricks.com/healthcare/how-get-there or http:// www.energystar.gov/index.cfm?c=guidelines.guidelines_index for more information.)

\section{Low-cost/no-cost metering steps include:}

$\square$ Look for any existing metering capabilities in your facility, and use what is in place before investing in new hardware. An increasing number of components in a building's electrical system come with some built-in energy metering capabilities. This is particularly true for equipment manufactured in recent years. Equipment to check includes:

Automatic transfer switches at electrical substations

Electrical distribution panels

Motor control centers, which may monitor power to exhaust fans, chiller auxiliaries, etc.

$\square$ VFDs

$\square$ Begin a program of monthly manual meter reading and recording of data into a dedicated energy database.

$\square$ Analyze data regularly to evaluate performance and identify opportunities for action.

Assess needs for future metering. 


\section{Ascension Health/Seton Family of Hospitals-Dell Children's Medical Center of Central Texas $\nabla$}

\author{
Location: Austin, Texas
}

Current Size: 176 beds; $515,000 \mathrm{ft}^{2}$

Planned Addition (early estimate): 72 beds; $75,000 \mathrm{ft}^{2}$

Functions: Intensive care and medical/surgical patient beds

Photo by Seton Family of Hospitals, used by permission.

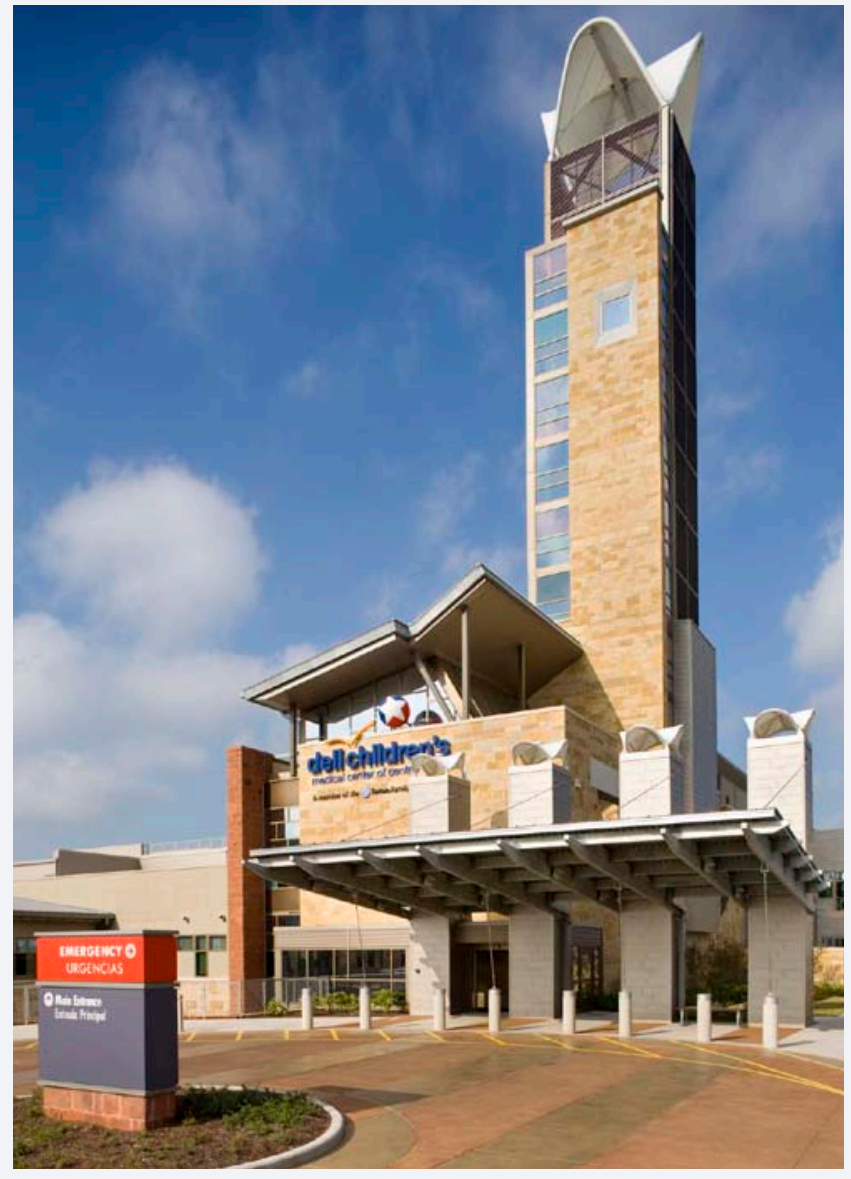

\section{Background $\nabla$}

When Dell Children's Medical Center of Central Texas was completed in 2007, it received a LEED ${ }^{\circledR}$ Platinum rating. One sign that the design has transitioned successfully to the operational phase is that the annual building energy consumption has been tracking within about $5 \%$ of design model predictions for the past two years.

In addition to these successes, hospital engineers also faced some challenges that have informed improvements to the health system's subsequent building designs. For example, Seton Family of Hospitals is applying lessons learned at the existing building to improve metering in a tower addition planned for 2013.

\section{Example: Steam Metering and Growth}

In anticipation of future growth, the steam piping was sized for more than 1 million $\mathrm{ft}^{2}$ of hospital floor area, and the steam meters for high-, medium-, and low-pressure steam were sized to match the piping. Consequently, the steam meter readings will be useful in the long term, but the flows in the near term are too low for the meters to provide accurate readings. The health system investigated solution options when the problem was discovered, but the taps were meter specific, and the vendor was unable to offer a workaround solution.

To improve future projects, owners should consider both present and future loads during piping design. In continuously operational facilities, solutions that do not require future interruption of steam supply will be favorable. If anticipated expansion is significant, solutions may include adjusting the piping design or metering key branches to allow for a more complete metering approach that captures steam use in both the near and long term.

Example: Site-Specific Product Considerations

Turbine meters were installed to measure hot and cold domestic water use in the existing building, but the hard water in Austin led to calcium deposits that prevented the meters from working properly. The owner will consider alternative meter designs in future projects to meter domestic water use as was originally intended. Throughout an integrated building design process, considering site-specifics can improve the success of metering efforts.

\section{Example: Anticipating Electrical Distribution Design Needs}

When an intraoperative magnetic resonance imaging (MRI) unit was added two years after building completion, the owners intended to monitor its energy consumption by metering panel loads in the shielded operating room. They soon discovered, however, that the original design did not account for metering due to complexities of the shielding. Radio frequency shielding requires all penetrations to be isolated, and in the case of power or signal wiring penetrations, the type and location of electrical filters are determined in coordination with the shielding vendor or contractor. Without such coordination during building design, it is difficult to implement changes later. Another complication is that electronic devices, including power monitors, cannot be placed within the shielded enclosure unless they are compatible with the MRI system.

Additionally, Seton Network Facilities reports that because the MRI power is coming directly from the main switchgear room rather than a new electrical room that was built for the project, metering the MRI would be difficult and cost prohibitive after the fact. The takeaway for other facilities is that design teams should evaluate prospective metering needs and plan electrical systems accordingly early in the design process. For example, if another facility were to encounter a similar case and identify the problem early enough, one solution 
could be to specify a "smart" breaker for the panel in the main switchgear room.

Dell Children's planned tower addition will not include major process or medical equipment, but a related improvement in its design process is that the owner is asking the design team to dedicate separate panels to lighting to support cost-effective submetering of the lighting load. Other target loads, such as air handler unit energy, are under consideration for panel segregation and metering.

Whether or not these loads are metered when the building opens, the key is that the discussion occurs early in the design process. By dedicating panels to a single type of load and planning electrical distribution at the outset, the owner will be able to cost-effectively install meters either during construction or as part of a future project.

\section{Recommended Steps for Hospitals $\nabla$}

The target audience for this approach includes health systems that are :

- Considering or proposing a new construction project.

- Starting the schematic design phase of a project.

The following approach is more likely to succeed for health systems that:

- Use an integrated design process.

- Engage their building operators early in the design process.

- Clearly document and communicate owner expectations to the design team.

\section{Steps to support cost-effective metering early in the design process include:}

$\square$ Identify monitoring capabilities that will be desired at project completion.

Identify monitoring capabilities that may be considered in the long term.

$\square$ Review planned and prospective additions to the building.

$\square$ Review planned and prospective changes to end uses, such as major medical equipment or process loads.

Work with the design team to identify and meet needs in electrical distribution design and component selection to enable both near and long term metering.

$\square$ Work with the design team to identify and meet needs in piping design and component selection to enable both near and long term metering.

Evaluate meter product options for limitations and site-specific considerations.

\section{Hospital Case 3} Getting the Most Out of Physical Meters

\section{Summa Health System-St. Thomas Hospital Campus $\nabla$}

Location: Akron, Ohio

Size: 200 beds; $570,000 \mathrm{ft}^{2}$, excluding parking deck

Functions: Inpatient, orthopedic surgery, psychiatry, transitional care

Photo by Summa Health System, used by permission.

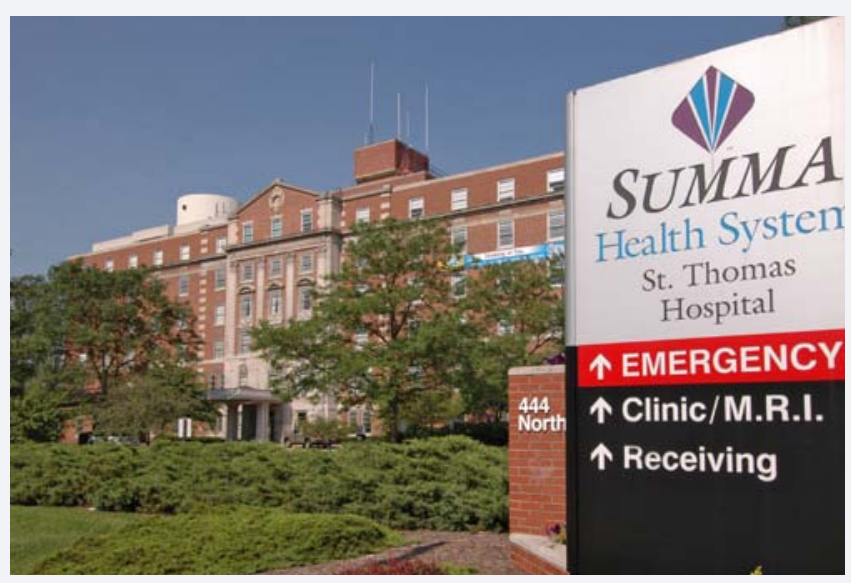

Background

Summa Health System began installing metering systems in the mid1980s. The accumulation of metering and software investments over time has provided Summa Health System with effective monitoring capabilities and the ability to cost-effectively expand those capabilities. Others who are considering expanding their metering efforts can use the lessons from this progression to inform their own plans.

Virtual Metering

The term virtual metering can be used in different ways. ${ }^{1}$ For this brochure, virtual metering is defined broadly as deriving a value for a point without a physical meter by examining values that are physically monitored elsewhere. Therefore, some physical meters must first be in place before virtual metering can be employed. Once an initial investment is made in physical meters, however, a virtual metering project can provide additional insight and decision-making capabilities at a lower cost than adding more physical meters.

One caveat is that a virtual metering solution may be less accurate than a physical one. In either case, owners should check proposed designs for acceptable accuracy and check installed meters periodically.

1. See End Notes on page 12. 
In cases where virtual data points can provide value, Summa Health System recommends installing only as many physical meters as necessary for staff to derive virtual values to accomplish a task. If the necessary physical data points are already being metered, smaller investments may include software applications or additional hardware such as input/output modules or cards that enable a communications link between a new VFD and an existing direct digital control system.

Converting Physical Data Into High-Impact Information and Action

While an evaluation of dashboards is outside the scope of this document, it is important to note that getting the full value from metering may require translating raw data into more usable forms. For example, the St. Thomas Hospital Campus boiler plant measured the amount of natural gas entering a boiler and the pounds of steam exiting the boiler. To monitor this information more effectively, Summa Health System staff constructed a dashboard that displays these values alongside the boiler efficiency derived from the input and output values and other information. Current values are graphically compared to past values and target values so a user can more easily identify underperformance and take corrective action.

\section{Recommended Steps for Hospitals $\nabla$}

The target audience for this approach includes health systems that have invested in physical metering.

The following approach is more likely to succeed for health systems that have:

- An established process for recording metered data

- Staff with assigned responsibility for regularly analyzing metered data.

\section{Steps to take to fully leverage existing physical meters include:}

Evaluate current capabilities.

Identify additional desired capabilities.

$\square$ Identify relevant end use categories and parameters to track (e.g., efficiency, energy output).

$\square$ Identify relevant benchmarks or baselines for comparison during operations, such as target values or values from previous operational periods (e.g., previous hour, previous month).

$\square$ Determine whether the desired capabilities can be achieved by leveraging existing data points and calculations rather than adding more physical meters.

$\square$ Assess whether deriving additional values from existing metered data or changing how data are reported would enable staff to better detect problems and take corrective action.

$\square$ If possible, leverage existing data points to achieve desired capabilities without adding software or hardware.

$\square$ If necessary, add software or small hardware investments, such as input/ output modules or cards.

Modify operational procedures to include use of the new capabilities.

Where possible, document savings that were indirectly enabled by new capabilities to help support future evaluation of metering.
Figure 2. Example dashboard with comparisons to past and target values $\nabla$ Photo by Mark Barich, Summa Health System, used by permission.

\section{Summa Health System, St. Thomas Hospital Campus Boiler Plant}

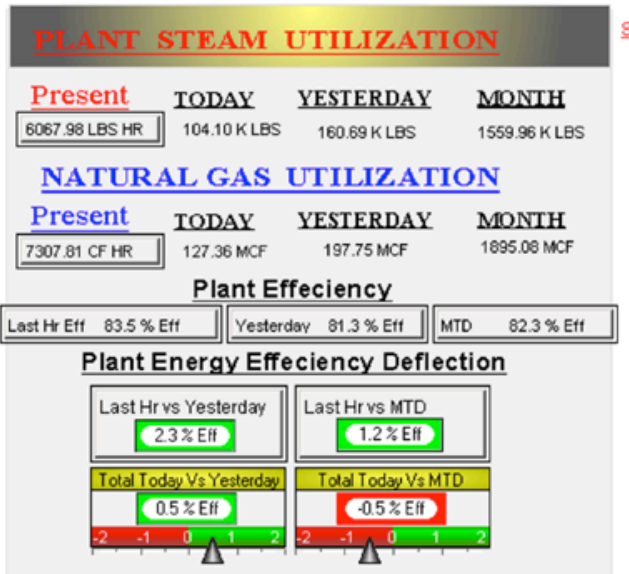

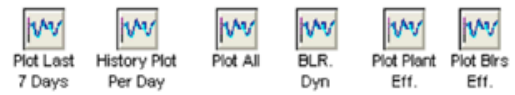

(1) Bir. Run Boler Perf.

A Summa Health System Hospital

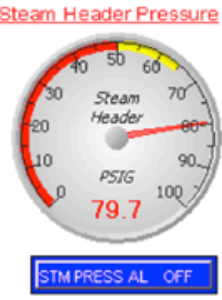

\section{Billing Poriod} MONTH 4 MONTH BILLING DAYS 12.0 DAY

Data Since DAY OF MON Reset $7.0 \mathrm{DA}$
Reset

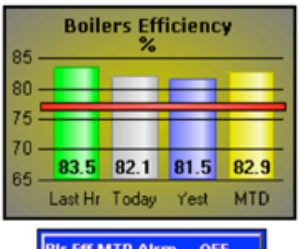
Bir Eff MTD Airm OFF
MN TIMER 45.92 OA Temp. $\quad 47.13 \mathrm{deg}$

R. LOAD STEAM PRODUCTIOIO

\section{NATURAL GAS UTILIZATION}

Present TODAY YESTERDAY MONTH

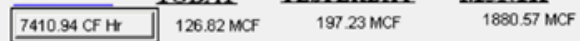

Steam Production Blrs. Effeciency Last Ht Eft $83.5 \%$ Eft Yesterday $81.5 \%$ Ett MTD $82.9 \%$ Eft Blrs. Energy Effeciency Deflection
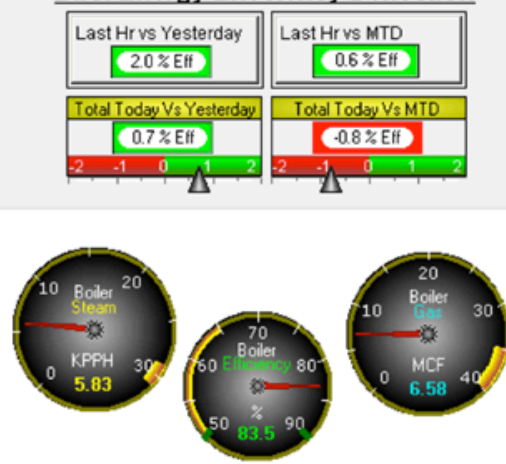

nt Live 1-Line Floor P \& $\neq$ \&
ubMeters Stm Absorber Load Shedding t. 


\title{
High-Priority Buildings and Spaces
}

Primary considerations for prioritizing buildings and spaces for metering should focus on whether additional metering would enable energysaving actions. Metered data can inform:

\author{
- Monitoring and verification of energy conservation measures \\ - Monitoring and verification of on-site power generation systems \\ - Improvements to operational procedures \\ - Retrofit decisions \\ - Programs to change occupant behavior
}

- A continuous improvement program that includes these elements.

Other considerations include whether peer-to-peer benchmarking is a priority for an organization. If so, a secondary consideration would be whether readily available tools such as EPA Portfolio Manager can compare the building in question to peer buildings. The March 2011 version of Portfolio Manager allows comparisons for certain healthcare buildings. Eligible hospitals include "acute care" and "children's hospitals" with a floor area of 20,000-5 million ft 2 ; a licensed bed count of 15-1,510; and a floor count of 1-40. Eligible medical offices have at least 5,000 $\mathrm{ft}^{2}$ of floor area; 30-168 operating hours per week; and at least one worker on the main shift (EPA 2011).

\section{Key Considerations When Choosing Buildings or Spaces To Meter $\nabla$}

\section{For each building or space, consider whether any of the fol- lowing conditions apply. If more of these conditions are true for a particular building or space, it will tend to be a better target for early metering investments.}

The building or space has known energy issues that would be easier to monitor and mitigate with added metering.

The building or space has implemented energy conservation measures that require monitoring and verification to ensure success.

Similar buildings or spaces have been observed to be relatively high energy users elsewhere in the owner's portfolio or in peer portfolios.

The building has clear energy goals.

The building has clear "green building" certification goals.

The building is hosting an on-site power generation system.

With metered energy data, the owner could influence behavior in:

Owner-occupied buildings or spaces.

Leased buildings or spaces where the lease structure causes the tenant's energy bill to vary with tenant energy use.

The building can be compared to other buildings through:

Internal benchmarking methods for intra-portfolio comparison.

External benchmarking tools for peer-to-peer comparisons, such as EPA Portfolio Manager.

\section{High-Priority End Uses}

Prior research and feedback from hospitals do not point to a definitive order of importance among potential targets for metering investments, but they do suggest a number of important considerations that should be included in the decision-making process when health systems are planning their metering investments.

One indicator of end use priority is its energy consumption relative to other end uses. DOE is sponsoring a hospital end use monitoring study that will collect data in 2011-2012 and should greatly improve the understanding of end use breakdowns and energy profiles.

In the meantime, hospitals lack reliable estimates of typical end use breakdowns, but a few sources of rough estimates of end use energy can be used as interim guidance.

\section{Modeled Estimates of End Use Energy Breakdowns}

While end use monitoring efforts are underway, healthcare facility owners could consider model-based estimates of end use energy breakdowns when prioritizing metering investments. One such estimate is depicted in Figure 3. The values are derived from modeled end use estimates in the 2003 Commercial Buildings Energy Consumption Survey (CBECS) conducted by DOE (EIA 2008). Another estimate is depicted in Figure 4. The values are national weighted averages of simulated results for climate zones across the United States based on the DOE Reference Buildings for new construction (DOE 2010).

\section{Early Loads to Investigate for Potential Metering Points}

The modeled estimates in Figure 3 and Figure 4 are not associated with an actual metered facility, and they are not sufficiently accurate to point to a ranked order of metering priorities. They do suggest, however, that certain loads are generally worth earlier investigation. 


\section{Considerations When Prioritizing Metering Investments}

Figure 3. Modeled estimates of healthcare end use energy (adapted from CBECS 2003) $\nabla$

Source: by CBECS, Figure by Raymond David, NREL

Inpatient CBECS Model Estimate

Outpatient CBECS Model Estimate

* Modeled values for outpatient cooking are not available.

Figure 4. Modeled estimates of healthcare end use energy (adapted from DOE Reference Buildings) $\nabla$

Source: by DOE, Figure by Raymond David, NREL

Hospital Reference Model Estimate

Outpatient Healthcare Model Estimate

In particular, heating, cooling, lighting, fans/ventilation, and plug/ process equipment are suspected to consume greater energy than other end uses in a typical healthcare facility. These general indications can be combined with site-specific needs to determine where first efforts should be spent in conducting feasibility assessments and requesting quotes for metering products and services.

\section{Additional considerations include:}

- Heating, ventilation, and air conditioning (HVAC): As discussed in the PeaceHealth example, energy data for some loads can be extracted from VFDs, motor control centers, certain kinds of electrical distribution panels, and automatic transfer switches. In other cases, metering of heating, cooling, fan, and pump energy can require more substantial investments. Costs may be even higher if metering capabilities were not considered during the initial design of electrical or piping distribution systems.
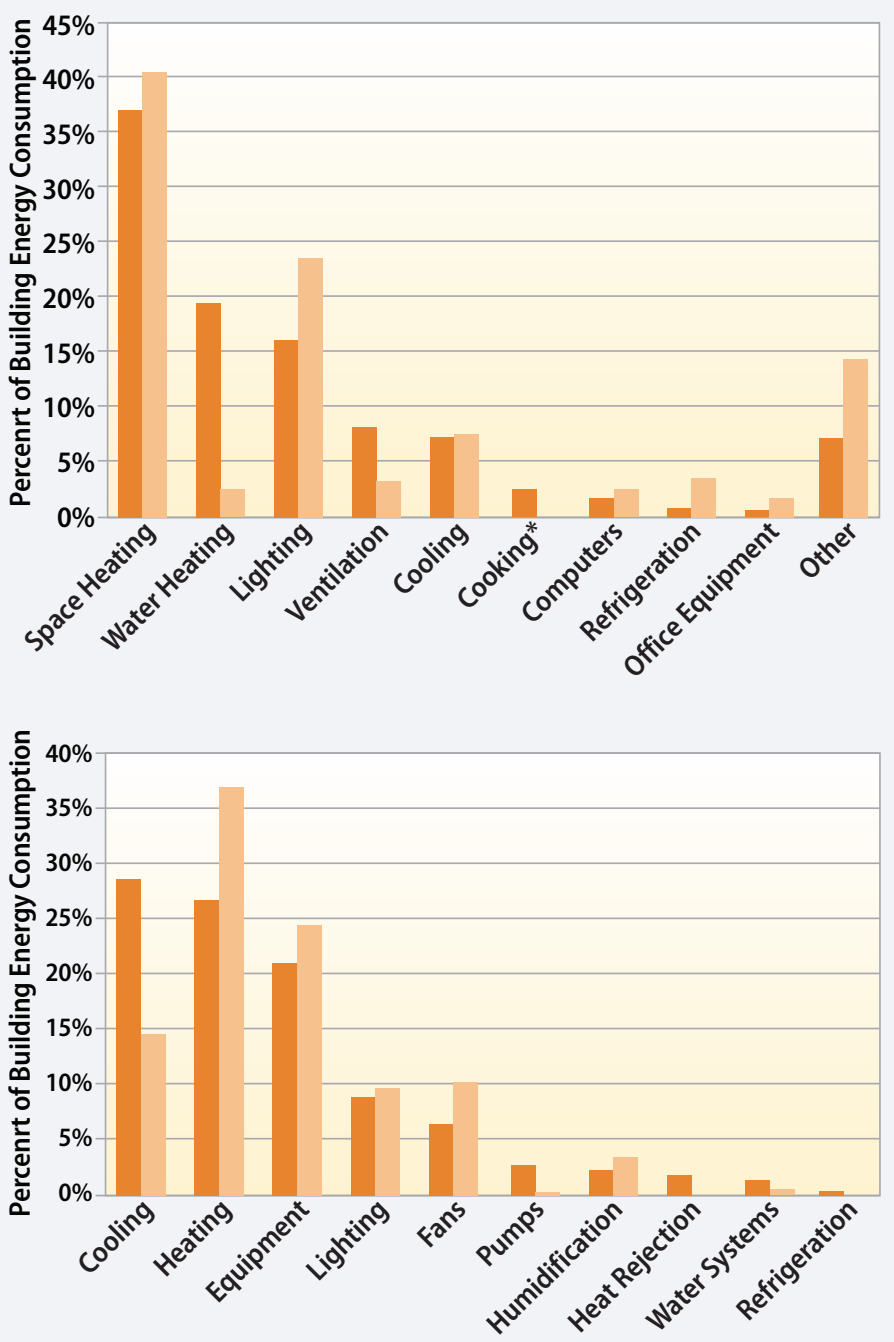

Within space heating, reheat is one of the greatest opportunities for improving energy efficiency. In a study of simulated hospital designs in multiple U.S. climates, researchers found that the design measure that saved the most energy was a change in HVAC system type that virtually eliminated reheat (Bonnema et al. 2010). Similarly, in a study of northwest U.S. hospitals, researchers reported that reheat in ducted air cooling systems accounted for most of the space heating energy consumption (Burpee et al. 2010). The tremendous benefit of reheat reduction in new construction suggests that reheat would also be a high priority for monitoring, control, and mitigation in existing buildings.

- Lighting: Submetering of lighting loads can help owners verify that sensor-based lighting controls are functioning as intended. It can also help identify suboptimal behavioral patterns in areas with manual switching. Submetering of lighting is generally easier and more cost effective if lighting circuits were segregated from other loads during initial electrical panel design. 


\section{Considerations When Prioritizing Metering Investments}

- Medical equipment: The scope of metering will depend on how the owner plans to use the metered data, as well as the electrical distribution in the building. If the owner is interested in monitoring major stationary medical equipment collectively, and if all the equipment of interest is on a segregated electrical branch or group of segregated panels, the metering scope may be more straightforward than if the branches and panels host a mix of end uses.

Alternatively, if the intent is to monitor individual equipment usage patterns or verify that certain equipment is switched off when not in use, it may be advantageous to meter at a more detailed level.

- State and local codes: Building owners in states without submetering requirements may wish to monitor trends elsewhere to inform their metering prioritization.

One example of a code with more specific requirements is the 2009 edition of the Washington state energy code, which went into effect in 2011 (State of Washington 2009). Table 12-2 of the code lists the power thresholds that lead to required submetering:

- Chillers/heat pump systems $>70 \mathrm{~kW}(240,000 \mathrm{Btu} / \mathrm{h})$ cooling capacity

- Packaged air conditioning unit systems > 70 kW (240,000 Btu/h) cooling capacity

- HVAC fan systems $>15 \mathrm{~kW}(20 \mathrm{hp})$

- Exhaust fan systems $>15 \mathrm{~kW}(20 \mathrm{hp})$

- Make-up air fan systems > 15 kW (20 hp)

- Pump systems $>15 \mathrm{~kW}(20 \mathrm{hp})$

- Cooling tower systems $>15 \mathrm{~kW}(20 \mathrm{hp})$

- Boilers, furnaces, and other heating equipment systems $>300$ kW (1 million Btu/h) heating capacity

- General lighting circuits > 15 kVA

- Miscellaneous electric loads > 15 kVA.
Key Considerations When Choosing End Uses To Meter $\nabla$

For each end use, consider whether any of the following conditions apply. If more of these conditions are true for a particular end use, it will tend to be a better target for earlier metering investments.

It is related to known energy issues that would be easier to monitor and mitigate with added metering.

Metering it will support monitoring and verification efforts to ensure success of current energy conservation measures.

Metering it will inform energy-efficient design and implementation of future energy conservation measures or on-site power generation systems.

Metering it will inform the design and execution of demand response/load shedding programs.

Metering it will enable the owner to motivate behavioral changes related to occupant controls.

Metering it will inform energy-efficient design and construction of other buildings or additions in the health system.

Metering it will help operators modify procedures and meet energy goals.

Metering it will help owners meet "green building" certification goals.

It is suspected of being a high energy consumer relative to other end uses.

\section{Example Template 1}

\section{Language for a Metering Data Acquisition System Request for Proposal}

Some products and services associated with metering may require a subcontract with an external provider. Such arrangements can vary in scope and duration, ranging from meter installation only to long-term data collection and delivery. The following template (in light yellow) includes content that health systems could customize and insert into a request for proposals (RFP) for metering equipment and data acquisition system (DAS) services. The language was adapted from previous RFP materials generated by the National Renewable Energy Laboratory. 


\section{X.1 Scope of Work}

The Subcontractor shall design and install a data acquisition system (DAS) for the hospital and collect and deliver to [Hospital XXXX] the detailed energy end use data. The time series energy end use data will be collected over a period of [XXXX] and will be disaggregated by major end use.

Note: If the hospital owner has already decided which loads to meter, the owner can list the loads here.

Alternatively, if the owner has some sense of its metering priorities but also wishes the RFP respondent to exercise its own judgment in prioritizing metering, the owner could include a statement such as:

In order of priority, the following major energy end uses are of interest:

1. [End use $X X X X]$

2. [End use $X X X X]$

3. [End use $X X X X]$

The Subcontractor shall provide documentation of the proposed DAS to [Hospital XXXX] that includes:

- Detailed description of all monitoring equipment in the DAS

- Location of monitoring equipment on a one line electrical diagram

- Paragraph form of the operating plan for the DAS, which should address installation and calibration, data storage capacity, and quality control

- Expected accuracy of the DAS and a first estimate of system measurement uncertainty

- Overall schedule, including procurement time, installation time, and the date the DAS will be online and fully functional

- List of major energy end uses that will be measured by the DAS

- List of major space types measured by the DAS and the degree to which they will be measured

- List of independent variables that can be recorded by the DAS or added to the DAS datasets (for example, ambient conditions, number of inpatients per unit time, number of imaging scans per unit time, etc.).

\section{X.2 Tasks}

\section{X.2.1 Design the Data Acquisition System}

The Subcontractor shall design the monitoring system to determine how each facility uses energy. This should be disaggregated by each required metered end use that is outlined in the scope of work.

Note: Depending on the project, some of the bullets may not be applicable and could be removed.

- The DAS will facilitate remote monitoring of all the measured points back to a central data logger, and [Hospital XXXX] will have remote real-time access to the data.

- The DAS should be able to resolve energy end use over time intervals of 15 minutes or less.

- The DAS should have measurement uncertainties not greater than $\pm 5 \%$.

- The priorities of the DAS should be to measure the major end users of energy in each specific hospital with emphasis on [end use XXXX, end use XXXX, and end use XXXX].

- If it is not feasible to measure all duplicate or replicated equipment, a plan should be communicated as to how the total energy use by load type will be extrapolated. 
- The DAS should also be able to distinguish energy end use by space type (operating room, patient room, imaging, cafeteria, etc...).

Note: If space-level metering is not part of the current scope of work, add at the end of this bullet, "...to facilitate potential space-level metering in the future."

- The use of electric receptacle end metering is highly discouraged for this application because the current associated technology has limited cost effectiveness and data collection capabilities.

- The addition of an outdoor weather station or the ability to accurately monitor the building ambient conditions via time series data is necessary.

- The ability to trend other independent variables such as the number of inpatients, outpatients, surgeries, and imaging scans, is also necessary.

- Any pre-existing monitoring equipment used as part of the DAS must also satisfy the previous requirements.

\section{X.2.2 Data Acquisition System Installation}

The Subcontractor shall install the DAS. The installation should be coordinated so that, if possible, daily hospital routines are not disrupted or impeded. Every measure should be taken to keep the DAS out of sight of the hospital occupants. Unauthorized access to the DAS and its components should be prohibited to maintain data integrity and ensure safety.

The Subcontractor shall also properly calibrate the DAS according to manufacturer's recommendations.

The Subcontractor shall ensure that the DAS installation is in compliance with any building codes or other governing authorities and does not violate any equipment warranties.

\section{X.2.3 Operate and Maintain the Data Acquisition System}

The Subcontractor shall maintain and operate the equipment according to the manufacturer's recommendations, including calibrations for a period of [XXXX]. This includes any pre-existing DASs at the site used to provide data for this project. The Subcontractor shall maintain a record of maintenance activities and events such as power outages, storms, or other events that might affect DAS performance.

The Subcontractor shall verify each day that the DAS is operating without fault by means of an energy balance or other method that must be approved in advance by [Hospital XXXX]. [Hospital XXXX] should also have access to real-time data from the DAS.

\section{X.2.4 Collect and Deliver the Energy End Use Data}

The Subcontractor shall collect time series end use energy data for a period of [XXXX] and the data will be delivered to [Hospital XXXX] each month. The data will be archived in a comma-separated-variable (.CSV) file and use a file naming convention such that the name of the file contains the year, month, and a unique site identifier. The Subcontractor shall format the files such that the data are "column data" with each column having a data identifier. Each row or line of data will consist of the data element, time stamp data, and units of measurement. If more than one DAS is used to measure the data, the Subcontractor shall merge the data into a single archived file.

\section{Example Template 2}

\section{Language To Support Metering Within a Building Design Request for Proposal}

The following template includes metering-related language that owners could customize and insert into a larger RFP for a building design project. The language was adapted from previous RFP materials for a "design-build" new construction project for the National Renewable Energy Laboratory. 


\section{X.1 Metering and Control}

\section{Electrical power monitoring and control}

a. Provide a complete system that can monitor the demand, consumption, and power quality at designated points in the electrical power distribution system.

b. Provide a system that is compatible in all respects, including equipment and software, with [system/service/product XXXX].

Note: Use this section to specify products if there are special requirements for compatibility with existing infrastructure.

c. Include remote devices for monitoring and protective functions; device communication interface hardware; intercommunication wiring; analysis software; and accessories as specified and indicated.

d. Metering will be designed and arranged so that the following electrical loads are measured independently:
i. Total building load
ii. [end use XXXX] load
iii. [end use XXXX] load

Note: Use this section to specify loads that are seen as a high priority for metering, such as lighting, mechanical equipment, etc.

\section{District cooling, district heating, and delivered fuels}

a. Metering will be designed and arranged so the following quantities of energy delivered to the building are measured independently as follows:

i. District chilled water

ii. District hot water

iii. District steam

iv. Fuel delivered to the site for on-site combustion:

- Natural gas

- Fuel oil

b. Products:

Note: Use this section to specify products if there are special requirements for compatibility with existing infrastructure. If there are no such requirements, you could omit this section, or write "Products to be specified by Design-Builder".

\section{Water}

a. Metering will be designed and arranged so the following water loads are measured independently:
i. [end use $X X X X]$
ii. [end use $X X X X$ ]
iii. [end use XXXX]

Note: Use this section to specify loads that are seen as a high priority for metering. Examples include make-up water systems, evaporative cooling systems, and irrigation.

b. Products:

Note: Use this section to specify products if there are special requirements for compatibility with existing infrastructure or local conditions (e.g., hard water). If there are no specific requirements for this section, you omit this section, or write "Products to be specified by Design-Builder."

\section{Data Collection and Reporting Requirements:}

Note: See Example Template 1 for content ideas.

This example is written to support a "design-build" process, but the concept of establishing metering requirements early in design can be adapted for other procurement methods. For example, in a "design-bid-build" process, similar requirements could be communicated directly by the owner to the architect and engineer during conceptual design. 


\section{Additional Resources}

\section{Healthcare Facility Resources}

In the April 2009 version of the U.S. Department of Veterans Affairs Electrical Design Manual (Interim), see "Section 5.4 Power Monitoring and Metering" for an example of what one healthcare facility owner requires for metering in its facilities.

- U.S. Department of Veterans Affairs. (2009). Electrical Design Manual (Interim). Accessed from http://www.cfm.va.gov/til/dManual.asp.

\section{General Resources}

These Federal Energy Management Program documents address a federal buildings audience, and they are not hospital specific, but they include general introductory information on such metering topics as planning, approaches, technologies, communications and data storage, data analysis and use, economics, and case studies.

- Federal Energy Management Program. (2006). Guidance for Electric Metering in Federal Buildings. http://www1.eere.energy. gov/femp/pdfs/adv_metering.pdf.

- Federal Energy Management Program. (2007). Metering Best Practices: A Guide to Achieving Utility Resource Efficiency. http:// www1.eere.energy.gov/femp/pdfs/mbpg.pdf.

\section{References}

BetterBricks. Accessed March 3, 2011, from http://www.betterbricks. com/healthcare/how-get-there.

Bonnema, E.; Studer, D.; Parker, A.; Pless, S.; Torcellini, P. (2010). Large Hospital 50\% Energy Savings: Technical Support Document. Golden, CO: National Renewable Energy Laboratory, NREL/TP-550-47867. http://www.nrel.gov/docs/fy10osti/47867.pdf.

Burpee, H.; Loveland, J. (2010). Targeting 100! Envisioning the High Performance Hospital: Implications for a New, Low Energy, High Performance Prototype. http://www.integrateddesignlab.com/Seattle/ Resources/HD_Research.html.

DOE. (2010). Commercial Reference Buildings, Version 1.3_5.0. http:// www1.eere.energy.gov/buildings/commercial_initiative/new_construction.html.

EIA. (2008). 2003 Commercial Buildings Energy Consumption Survey. "Estimation of End-Use Energy Consumption." http://www.eia.gov/ emeu/cbecs/tech_end_use.html.

EPA. (2011). Criteria for Rating Building Energy Performance: Operating Characteristics. Updated March 2011. http://www.energystar.gov/ ia/business/evaluate_performance/OperatingCharacteristics.pdf.
Energy Efficiency Best Practice Programme. (2002). Metering Energy Use in New Non-Domestic Buildings: A Guide To Help Designers Meet Part L2 of the Building Regulations. General Information Leaflet 65. http://www.cibse.org/pdfs/GIL065.pdf.

Green, D.C.; Allen, P.J. (2005). Chapter 12: Using Virtual Metering to Enhance an Energy Information System. From Web Based Energy Information and Control Systems: Case Studies and Applications, edited by Capehart, B.L.; Capehart, L.C.

Mahling, D.E.; Paradis, R.; O'Connor, W.; Kruthofer, S. (2007). Chapter 9: How to Automate Strategies that Make Companies Energy Savvy. From Web Based Enterprise Energy and Building Automation Systems, edited by Capehart, B.L.; Capehart, L.C.

State of Washington. (2009). Washington State Energy Code. WAC 51-11-1200. Section 1201 - General. Chapter 12: Energy Metering. http://apps.leg.wa.gov/WAC/default.aspx?cite=51-11.

\section{Acknowledgments}

This document was produced in collaboration with the Commercial Building Energy Alliances, a partnership sponsored by the U.S. Department of Energy (DOE). The authors would like to thank the DOE Building Technologies Program for its support.

The Center for Electricity, Resources, and Building Systems Integration at the National Renewable Energy Laboratory (NREL) led the production of this document. Data gathering support and review was also provided by the Lawrence Berkeley National Laboratory (LBNL).

Several health system representatives contributed content for this document. Mark Barich of Summa Health System, Scott Dorough of PeaceHealth, Phil Risner of Seton Family of Hospitals, and Dan Scher of Ascension Health provided example successes, lessons, and recommendations. Pat Lydon of Legacy Health also provided input on cost model considerations. Thank you to these and other members of the Hospital Energy Alliance's Benchmarking and Measurement Project Team for sharing their lessons and challenges for the benefit of the greater healthcare community.

\section{End Notes}

${ }^{1}$ In the utility billing context, virtual metering sometimes refers to virtual meter aggregation programs in which multiple physical meters are virtually combined for the purpose of reducing peak demand charges (Mahling et al. 2007). This can reduce bills when metered loads peak at different times during a given billing period: in such cases, the peak demand at the aggregate meter would be less than the sum of the smaller meters' peak demands for that billing period. Virtual metering can also refer to a prorated assignment of energy use to tenant spaces that are not individually metered, or to the calculation of energy consumption at one point by subtracting values that are physically metered at two other points (Green et al. 2005). A related term, indirect metering, is sometimes used to refer to the derivation of energy consumption from monitoring other physical properties, such as cold feedwater usage and temperature differences (EEBPP 2002). 